\title{
ANÁLISE MORFOFISIOLÓGICA E VIABILIDADE DE PLANTAS DE Orthophytum mucugense Wand.e Conceição CONSERVADAS IN VITRO Amanda Lima Pinheiro ${ }^{1}$; Alone Lima Brito ${ }^{2}$; Andressa Priscila Piancó Lima ${ }^{3}$ \\ 1. Bolsista PIBIC/FAPESB, Graduando em Agronomia, Universidade Estadual de Feira de Santana, e-mail: amanda_pinheeiro@hotmail.com \\ 2. Orientadora, Departamento Ciências Biológicas, Universidade Estadual de Feira de Santana, e-mail: lima_brito@yahoo.com.br \\ 3. Doutoranda, Recursos Genéticos Vegetais Universidade Estadual de Feira de Santana, e-mail: andressapianco@gmail.com
}

PALAVRAS-CHAVE: Conservação in vitro; capacidade regenerativa; bromélias.

\section{INTRODUÇÃO}

Entre os gêneros de bromélias encontrados na Cadeia do Espinhaço está o Orthophytum (VERSIEUX et al., 2008). No estado baiano, é encontrada a espécie Orthophytum mucugense (Wand.e Conceição). Os relatos acerca da sua distribuição geográfica revelam que a sua ocorrência está restrita ao município de Mucugê - Chapada Diamantina (BELLINTANI, 2006). Esta espécie é considerada vulnerável por seu endemismo e por ser alvo de extrativismo (LIMA et al. 2012) sendo necessários estudos que visem a conservação desta espécie.

A cultura de tecidos vegetais pode ser uma opção viável para a conservação ex situ de $O$. mucugense através do crescimento mínimo. Esta técnica permite que uma grande quantidade de plantas seja conservada em um espaço físico reduzido, sem os riscos existentes no campo e mantendo a fidelidade genética, o que garante assim a disponibilidade de material para o intercâmbio de germoplasma e estudos de melhoramento genético (FARIA et al., 2006).

Não há relatos de estudos de conservação in vitro para $O$. mucugense, portanto o objetivo deste trabalho foi avaliar os aspectos morfofisiológicos e a viabilidade das plantas de Orthophytum mucugense submetidas a conservação in vitro.

\section{MATERIAL E MÉTODOS}

Os experimentos foram realizados no Laboratório de Cultura de Tecidos Vegetais (LCTV) da Unidade Experimental Horto Florestal pertencente a Universidade Estadual de Feira de Santana (UEFS). Foram utilizadas plântulas estabelecidas in vitro oriundas de sementes coletadas no Parque Nacional de Mucugê, município de Mucugê na Chapada Diamantina - BA.

As plântulas foram inseridas em tubos de ensaio $(25 \times 150 \mathrm{~mm})$ contendo $18 \mathrm{ml}$ de meio de cultura MS $1 / 2$ gelificado com 7 g. $\mathrm{L}^{-1}$ de ágar, e diferentes concentrações de sacarose combinadas ou não com manitol, totalizando cinco tratamentos.

O delineamento experimental foi o inteiramente casualizado (DIC) com 40 tubos por tratamento. Cada tratamento foi composto de dez repetições e quatro amostras por repetição (um explante por tubo). Em todos os experimentos o $\mathrm{pH}$ do meio de cultura foi ajustado para 5,8 e a esterilização foi realizada em autoclave a $120^{\circ} \mathrm{C}$ por 15 minutos.

Foram feitas avaliações mensais da sobrevivência das plantas, e após 300 dias de conservação foram avaliadas a porcentagem de sobrevivência $(\% \mathrm{~S})$, porcentagem de plantas com brotos $(\% \mathrm{~PB})$ e número de brotos por planta (NBP), considerando todas as amostras de cada tratamento. Já para as análises de crescimento foram utilizadas 15 
amostras de cada tratamento e foram avaliados: número de folhas verdes (NFV), número de folhas senescentes (NFS), comprimento da parte aérea (CPA), comprimento da maior raiz (CMR), número de raízes (NR), matéria fresca da parte aérea (MFPA) e da raiz (MFR), matéria seca da parte aérea (MSPA) e da raiz (MSR), o teor de clorofila e a capacidade regenerativa.

A determinação do teor de clorofila foi realizada de acordo com a metodologia de Arnon (1949) com ajustes. Para tanto folhas verdes sadias foram destacadas das plantas conservadas in vitro e pesadas $0,5 \mathrm{~g}$ para cada amostra. Posteriormente estas folhas foram maceradas com $15 \mathrm{ml}$ de acetona $80 \%$ e depois filtradas em papel filtro. A parte filtrada foi completada com acetona $80 \%$ para $25 \mathrm{ml}$ e depois foi realizada a medida da absorbância em espectofotômetro nos comprimentos de onda de 645 e $663 \mathrm{~nm}$.

Explantes caulinares com $0,5 \mathrm{~cm}$ e explantes foliares basais e radiculares com $1 \mathrm{~cm}$ de comprimento foram inseridos em tubo de ensaio contendo $15 \mathrm{ml}$ de meio de cultura suplementado com 30g.L de sacarose e 0,7\% de ágar acrescido de 2,60 de ANA para os explantes caulinares (LIMA et al., 2015a) e 5,0 de 2,4 D para explantes radiculares e 5,0 de 2,4D com 2,5 de BAP para explantes foliares (LIMA et al., 2015b).

Para cada explante o delineamento foi inteiramente casualizado com 5 repetições e 5 amostras por repetição. Após 30 dias foram avaliadas a porcentagem de explantes responsivos e o número de brotos por explante.Os experimentos foram mantidos em sala de crescimento com temperatura de $26 \pm 3^{\circ} \mathrm{C}$, fotoperíodo será de $16 \mathrm{~h}$ e radiação fotossintética ativa de $60 \mu \mathrm{mol} \mathrm{m} \mathrm{m}^{-2} \mathrm{~s}^{-1}$. Os dados foram submetidos à análise de variância (ANOVA) utilizando o programa estatístico SISVAR 5.1 e as médias comparadas pelo Teste de Tukey a $5 \%$ de probabilidade.

\section{RESULTADOS E DISCUSSÃO}

De acordo com a análise de variância a porcentagem de sobrevivência das plantas conservadas após 270 dias não foi influenciada pelo tratamento testado $(p \geq 0,05)$. Foi obtida uma alta taxa de sobrevivência no experimento, sendo ela de 97,5\%.

Para o NFV as médias obtidas nos tratamentos T3 e T4 os quais tiveram sacarose e manitol combinados foram superiores as dos tratamentos T1 e T2 suplementados com as maiores concentrações de sacarose, mas não diferiram estatisticamente entre si e do controle (Tabela 1).

Para o NFS a média obtida no T3 $(5,46)$ com sacarose e manitol foi estatisticamente inferior as médias dos tratamentos T1 $(21,00)$ e T2 $(19,06)$, e não diferiu estatisticamente do T4 (10,73), também composto por estas duas substâncias, e ambos não diferiram do controle $(16,26)$ (Tabela 1).

Para CPA a média 5,51 obtida no controle com 30 g. $\mathrm{L}^{-1}$ de sacarose foi significativamente inferior à do T2 $(6,72)$ com a maior concentração de sacarose 60 g.L $\mathrm{L}^{-1}$ (tabela 1).

As médias para CMR obtidas nos tratamentos controle com $30 \mathrm{~g} . \mathrm{L}^{-1}$ de sacarose e T3 com sacarose e manitol não diferiram entre si e foram significativamente inferiores às dos tratamentos T1 e T2 os quais continham as maiores concentrações de sacarose $\left(45\right.$ e 60 g.L $\mathrm{L}^{-}$ ${ }^{1}$, respectivamente), e não diferiram também do T4 (Tabela 1). Para o NR os tratamentos T2 e T4 apresentaram médias significativamente superiores à do controle (Tabela 1). 
Tabela 1. Efeito dos agentes osmóticos sacarose e manitol no número de folhas verdes (NFR), número de folhas senescentes (NFS), comprimento da parte aérea (CPA), comprimento da maior raiz (CMR), número de raízes (NR), massa fresca da raiz (MFR), massa seca parte aérea (MSPA) e massa seca da raiz (MSR) das plantas Orthophytummucugense conservadas in vitro durante 300 dias.

\begin{tabular}{ccccccc}
\hline Tratamento & Sacarose & Manitol & NFV & NFS & CPA $(\mathrm{cm})$ & CMR $(\mathrm{cm})$ \\
\hline Controle & 30 & 0 & $36,06 \mathrm{ab}$ & $16,26 \mathrm{abc}$ & $5,51 \mathrm{~b}$ & $3,74 \mathrm{~b}$ \\
T1 & 45 & 0 & $27,33 \mathrm{bc}$ & $21,00 \mathrm{a}$ & $6,02 \mathrm{ab}$ & $6,48 \mathrm{a}$ \\
T2 & 60 & 0 & $25,20 \mathrm{c}$ & $19,06 \mathrm{ab}$ & $6,72 \mathrm{a}$ & $7,26 \mathrm{a}$ \\
T3 & 30 & 7,8 & $37,93 \mathrm{a}$ & $5,46 \mathrm{c}$ & $5,82 \mathrm{ab}$ & $3,57 \mathrm{~b}$ \\
T4 & 45 & 7,8 & $39,26 \mathrm{a}$ & $10,73 \mathrm{bc}$ & $5,87 \mathrm{ab}$ & $5,74 \mathrm{ab}$ \\
\hline & & & NR & MFR $(\mathrm{g})$ & MSPA $(\mathrm{g})$ & MSR $(\mathrm{g})$ \\
\hline Controle & 30 & 0 & $4,93 \mathrm{~b}$ & $0,03 \mathrm{~b}$ & $0,06 \mathrm{~b}$ & $0,00 \mathrm{bc}$ \\
T1 & 45 & 0 & $6,46 \mathrm{ab}$ & $0,05 \mathrm{ab}$ & $0,08 \mathrm{ab}$ & $0,02 \mathrm{ab}$ \\
T2 & 60 & 0 & $7,26 \mathrm{a}$ & $0,08 \mathrm{a}$ & $0,09 \mathrm{a}$ & $0,02 \mathrm{a}$ \\
T3 & 30 & 7,8 & $6,86 \mathrm{ab}$ & $0,04 \mathrm{~b}$ & $0,06 \mathrm{~b}$ & $0,00 \mathrm{c}$ \\
T4 & 45 & 7,8 & $7,53 \mathrm{a}$ & $0,05 \mathrm{ab}$ & $0,07 \mathrm{ab}$ & $0,01 \mathrm{abc}$ \\
\hline
\end{tabular}

Médias seguidas pela mesma letra na coluna não diferem entre si pelo teste de Tukey a 5\% de probabilidade de erro.

Nota-se que as médias para MFR e MSPA tiveram o mesmo comportamento com a maior média no tratamento T2 que continha a maior concentração de sacarose, e diferiu estatisticamente do T3 e do controle os quais continham a menor concentração desta substância (30 g. $\mathrm{L}^{-1}$ ), mas não apresentou diferença significativa do T1 e T4 (Tabela 1). As médias dos tratamentos T1, T2 e T4, com as maiores concentrações de sacarose (45 e 60 g. $\left.\mathrm{L}^{-1}\right)$, não diferiram estatisticamente entre si e apresentaram os maiores valores para MSR (Tabela 1).

As melhores médias para \%EFRC - explantes foliares responsivos a formação de calos-foram obtidas para as plantas provenientes dos tratamentos T2, T3, T4 e T5 e não diferiram estatisticamente entre si, mas apresentaram diferença significativa em relação ao T1 (Tabela 2).

Tabela 2. Porcentagem de explantes foliares responsivos a formação de calos (\%EFRC) sobre efeito de 5,0 $\mu \mathrm{M}$ de 2,4-D com 2,5 $\mu \mathrm{M}$ de BAP em segmentos foliares de plantas conservadas por 300 dias em diferentes tratamentos com agentes osmóticos.

\begin{tabular}{cccc}
\hline \multicolumn{2}{c}{ Meio de Conservação } & \multicolumn{2}{c}{ Regeneração } \\
Sacarose & Manitol & $5 \mu \mathrm{M}$ & Tratamentos \\
& 0 & $\mathrm{~T} 1$ & \%EFRC \\
\hline 30 & 0 & $\mathrm{~T} 2$ & $24,99 \mathrm{~b}$ \\
45 & 0 & $\mathrm{~T} 3$ & $75,00 \mathrm{a}$ \\
60 & 7,8 & $\mathrm{~T} 4$ & $91,66 \mathrm{a}$ \\
30 & 7,8 & $\mathrm{~T} 5$ & $79,16 \mathrm{a}$ \\
45 & 0 & $70,83 \mathrm{a}$ \\
\hline
\end{tabular}

Médias seguidas pela mesma letra não diferem entre si pelo teste de Tukey a 5\% de probabilidade de erro.

Quanto ao teor de clorofila das plantas conservadas os tratamentos apresentaram diferenças significativas para clorofila $a$ e clorofila total. Para clorofila $a$ a média obtida no 
tratamento controle apresentou diferença estatística significativa das médias geradas nos tratamentos T2 e T3. Já para clorofila total o controle, suplementado com a menor concentração de sacarose 30 g.L $\mathrm{L}^{-1}$ e com o menor potencial osmótico, apresentou média estatisticamente superior apenas à do T2, que continha a maior concentração desta substância 60 g.L. $\mathrm{L}^{-1}$ e maior potencial osmótico (Tabela 3). Esses resultados indicam que possivelmente o estresse hídrico causado pela adição de agentes osmóticos ao meio de cultura interferiu na síntese de clorofila.

Tabela 3. Teor de clorofila $a$ e clorofila total das plantas conservadas por 300 dias em diferentes tratamentos com agentes osmóticos.

\begin{tabular}{ccccc}
\hline Tratamento & Sacarose & Manitol & Clorofila $a$ & Clorofila total \\
\hline Controle & 30 & 0 & $8,08 \mathrm{a}$ & $12,20 \mathrm{a}$ \\
T1 & 45 & 0 & $3,41 \mathrm{ab}$ & $4,82 \mathrm{ab}$ \\
T2 & 60 & 0 & $2,13 \mathrm{~b}$ & $3,62 \mathrm{~b}$ \\
T3 & 30 & 7,8 & $2,07 \mathrm{~b}$ & $4,73 \mathrm{ab}$ \\
T4 & 45 & 7,8 & $4,65 \mathrm{ab}$ & $7,57 \mathrm{ab}$ \\
\hline
\end{tabular}

Médias seguidas pela mesma letra nas colunas não diferem entre si pelo teste de Tukey a $5 \%$ de probabilidade de erro.

De modo geral o tratamento T4 contendo 45 g. $\mathrm{L}^{-1}$ associado a 7,8 g. $\mathrm{L}^{-1}$ de manitol apresentou bons resultados para as variáveis avaliadas, apesar de não ter diferido estatisticamente do tratamento controle para o CPA, NFV, NFS e CMR, apresentou melhores médias para MSPA, MSR e NR.

\section{CONSIDERAÇÕES FINAIS}

A associação de 45 g.L $\mathrm{L}^{-1}$ de sacarose com 7,8 g.L $\mathrm{L}^{-1}$ de manitol possibilita a conservação in vitro de $O$. mucugense por um período de 270 dias.

\section{REFERÊNCIAS}

BELLINTANI, Moema Cortizo. Estudos da propagação in vitro e ex vitro de Neoregelia mucugensis Leme, Orthophytum mucugense Wand e Conceição e Orthophytum albopictum Philcox, espécies de Bromeliaceae endêmicas da Bahia. 2006. 115p. Tese (Doutorado) Universidade Estadual de Feira de Santana, Feira de Santana, 2006.

FARIA, G. A. et al. Efeito da sacarose e sorbitol na conservação in vitro de Passiflora giberti NE Brown. Revista Brasileira de Fruticultura, p. 267-270, 2006.

FERREIRA, D.F. SISVAR Sistema de análises estatísticas. Lavras: UFLA, 2003. V.3, n.4.

LIMA, C. O. D. C.; MARCHI, M. N. G.; LIMA-BRITO, A.; CARNEIRO, C. E.; BELLINTANI, M. C.; SANTANA, J. R. F. d. Organogênese direta de Orthophytum mucugense. Ciência Rural. v.42, n. 2. 2012.

VERSIEUX, L. M. et al. Bromeliaceae da Cadeia do Espinhaço. Megadiversidade, v. 4, n. 1-2, p. 98-110, 2008.

WANDERLEY, M. das G. L.; CONCEIÇÃO, Abel Augusto. Notas Taxonômicas e uma nova espécie do gênero Orthophytum Beer (Bromeliaceae) da Chapada Diamantina, Bahia, Brasil. Sitientibus (Série Ciências Biológicas), Feira de Santana, v. 6, n. 1, p.3-8, 2006 